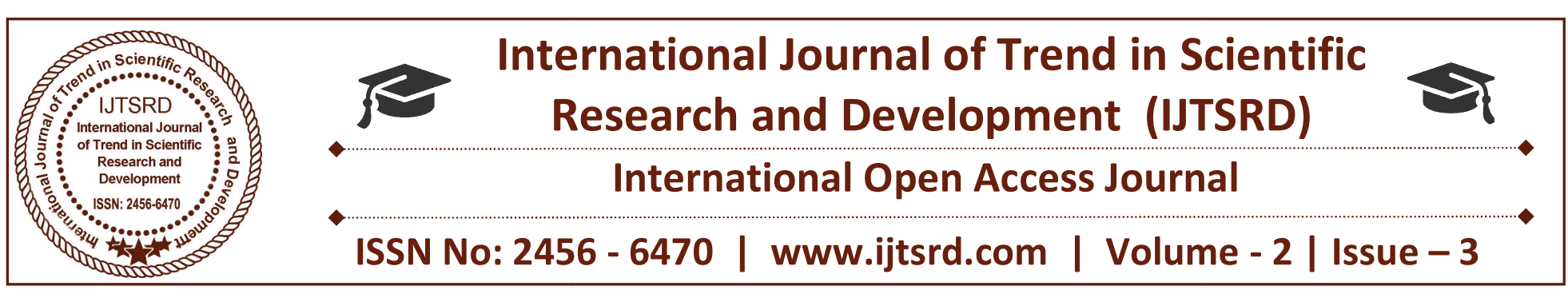

\title{
Critical Time -Motion and Economic Analysis of Linear and Rotary Gravity Conveyor for application One man multi-machine setup as low cost automation in material handling
}

\author{
Mr. Deokate A. Y. \\ Department of Mechanical \\ Engineering, BIT Barshi, \\ Solapur, Maharashtra, India
}

\author{
Prof. Mundhe V. L. \\ Head of Department of Mechanical \\ Engineering, BIT Barshi, \\ Solapur, Maharashtra, India
}

\author{
Dr. N. G. Narve \\ Principal, \\ Yashoda Technical Campus, \\ Satara, Maharashtra, India
}

\section{ABSTRACT}

The rapid growth of technology in the last two decades has been characterized by full automation. As only the affluent and developed countries can afford to adopt full automation, a large productivity gap has been created. This gap can be bridged through low cost automation. The concept and principles of low cost automation are basically the same as those of full automation except that the former builds improvement around existing equipment and machine system rather than replacing whole system with automated processes. Material handling is the primary activity of every manufacturing organization. It has been estimated that at least 15 to $25 \%$ of the cost of the product is attributable to material handling activities. Unlike many other operations, material handling adds to the cost of the product and not to its value. It is therefore important first to eliminate or at least minimize the need for material handling and second to minimize the cost of handling.

Karakuri mechanisms use a single force or motion to simultaneously perform multiple operations, and also lead directly to energy conservation and resource (facilities) savings. Conventionally gravity conveyors are used to perform material handling task but they are more often of fixed layout type with a singular application. The proposed linear gravity conveyor for flexible manufacture system uses the principle of Converting the force from a dropped weight into gear rotation to activate a conveyor thereby saving the cost of motor and electricity. Conveyors are ordinarily activated by using drive from a motor. In this example, when the conveyor is lifted with a cylinder, a weight drops from the top portion of the conveyor. The force of dropped weight rotates gears that provide movement needed for slide delivery of work (semifinished products). This mechanism eliminates the need for a motor and enabled a reduction in standby electricity and electricity for operation. Slide delivery requires only the necessary amount of driving energy at the time when needed and is therefore consistent with the concept of "just-in-time" electricity.

Objective of project is carry out critical analysis as to time-motion and economics of the developed conveyor system with linear and rotary conveyor to determine the i)Transfer time ii)Maximum load carrying capacity .Comparative analysis of the performance of the developed system with conventional conveyor to derive: Change in job transfer time.

\section{Problem Statement:}

\section{a) Linear Conveyor}

The present Linear Gravity conveyor is fixed type that is fixed length, fixed weight carrying capacity, high running cost, high power consumption \& not suitable to be used with multiple machines due to rigid \& 
heavy mountings, fixed length \& weight parameters \& also not suitable to flexible manufacturing system.

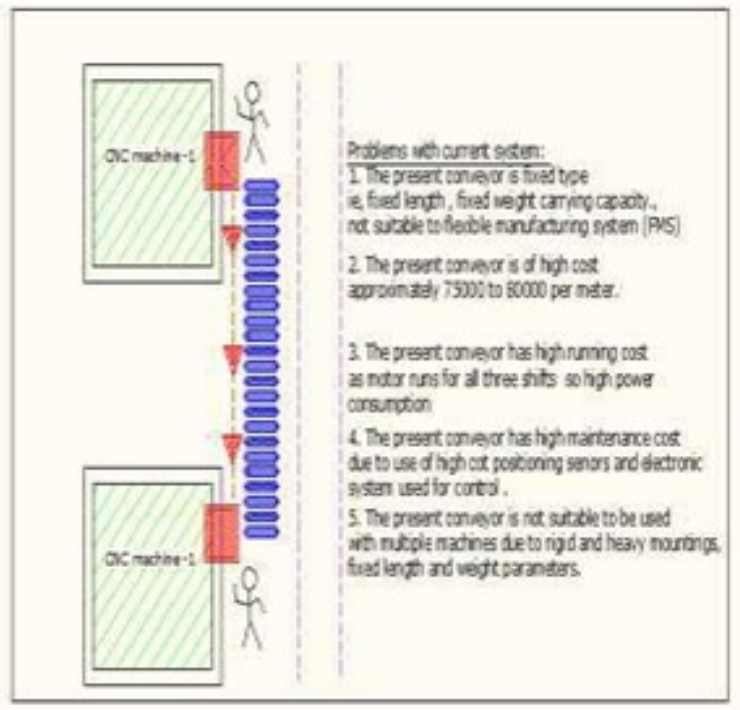

\section{b) Rotary Conveyor}

The present rotary conveyor plant layout becomes fixed type, blocks transits area and hence hampers material handling movement, high installation cost, continuous power requirement is required \& use of electronic equipment for position sensing hence maintenance cost is high

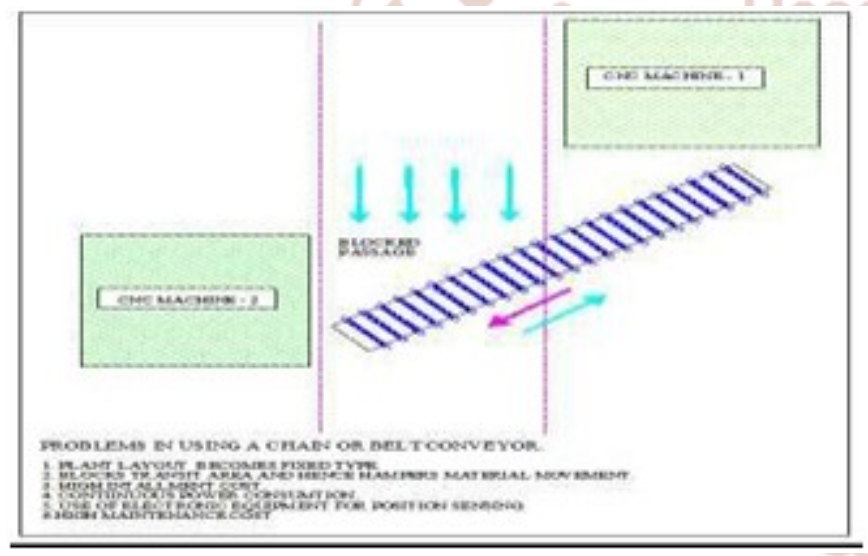

Hence there is need of innovative material transport system that is proposed to have following properties:

Conveyor should be modular i.e

i) Length of conveyor is to be adjustable to be able to connect any two machines spaced between 1 metre to 1.8 metre

ii) Weight carrying capacity of conveyor to be varied from $5 \mathrm{~kg}$ to $12 \mathrm{~kg}$ in tray system.

b) Conveyor should be powerless in operation :
This means that there conveyor is to be powered by gravity action so that there will be no running cost.

c) Conveyor weight carrying capacity should be made such that the conveyor system will automatically adjust the slide angle using a comparator and hydraulic dashpot mechanism to ensure that the job does not fall out of tray due to momentum of job at end of stroke.

\section{Literature Review}

Analysis and Optimization of Gravity Roller Conveyor Using Ansys [1]. The main objective of this study is to explore the analysis of Gravity roller conveyor. This has entailed performing a detailed Study of existing Gravity Roller Conveyor system and optimizes the critical part like roller, C-channel etc. by using composite material, so to minimize the overall weight of the assembly without hampering its structural strength. A proper Finite Element Model is developed using Cad software Pro/E Wildfire 5. Results of Static, Modal and Transient analysis of existing design and optimized design are compared. The material used for roller and C-channel frame is a composite material i.e. carbon fiber.

Study and Performance of Belt Conveyor System with Different Type Parameter [2].

Material handling equipment are designed for many advantage such as easy, cheap, fast and safe loading and unloading condition. Belt conveyor systems are design for easy handling of materials in terms of weigh: and height. This paper discusses the design and considerations of belt conveyor system for sample weight, in terms of size, length, capacity and speed, roller diameter, location and arrangement of pulley, angle and axis of rotation, control mode, intended application, product to be handled.

Gravity Flow Rack's Material Handling System for Just-In-Time (JIT) Production [3].

This paper presents a review on the actual implementation of a GFR system at an automotive component's assembly line in an accord to improve its existing $\mathrm{MH}$ system. The main purpose of this implementation is to reduce the material transfer activities while reducing the occupied space; hence reducing the overall production cycle time (CT). The implementation outcomes show push or gravity conveyors are ideal for significance improvement on the moving parts between workstations. Their 
productivity and not to mention the minimum complexity makes them easy to material handling's time. Service and minimizes down time.

\section{Scope of Work \& Objective:}

\section{a) Scope of Work}

In today's manufacturing environment, assembly work is routinely characterized by short production cycles and constantly diminishing batch sizes, while the variety of product types and models continues to increase. Constant pressure to shorten lead times adds to these demands and makes the mix truly challenging, even for the most innovative manufacturers.

1. The ability to respond quickly to rapidly changing customer demands requires the use of manufacturing systems that can be re-configured and expanded on the fly, and which can accommodate advances in assembly techniques without making any initial manufacturing investments obsolete. Although very heavy parts may be transported on belt conveyors, manual motion with objective to need and feasibility of implementation of low cost automation in material handling system.

2. Critical study of time, distance and motion study after implementation of linear rotary gravity conveyor system to present layout to determine the reduction in time, distance movement and machine downtime to derive the savings after implementation of the system.

3. Critical study of maximum load carrying capacity after implementation of linear rotary gravity conveyor system to present layout to determine the load carrying capacity after implementation of the system.

4. Comparative analysis of the linear gravity and rotary gravity conveyor systems with conventional method of material transfer to prove the effectiveness of new system over conventional or existing system.

\section{Methodology of Project:}

Primary work will be to do time and motion study for pilot study where in the targets of motion will be as follows:

Linear distance covered is $1 \mathrm{~m}$
Rotary distance covered is $1.5 \mathrm{~m}$

Net distance travelled is $2.5 \mathrm{~m}$

\section{The system will be studied and tested as per below:}

1) System design as to the number of components required, their sizes as per machine layout conditions

2) Selection of following parts:

3) Linear conveyor system components

4) Shock arresting machine at the end of stroke for linear conveyor

5) Rotary conveyor system components

6) Shock arresting machine at the end of stroke for Rotary conveyor

\section{A) Manufacturing of Set-Up}

1) Manufacturing of linear conveyor system

2) Manufacturing of Rotary conveyor system

3) Fabrication of combined set up to integrate both work motions to get net effect of conveyance

\section{Testing Of the Linear Conveyor For}

Following Parameters

Observations for Angle of inclination 8 degree incline

Theoretical Derivation of the Time Required For Job to Move:

Acceleration an on an inclined plane (with friction)

Determine the rate of deceleration of $7.0 \mathrm{~kg}$ block sliding up an inclined angle at $35^{\circ}$ to the horizontal. Assume that the coefficient of friction is 0.45 ,

Step I: Free body diagram

Step II: Calculate the component of any forces acting up or down the hill

In this case, these forces would include the forces of friction down the hill and component of gravity down the hill.

The component of gravity, $\mathrm{Fg}$

$F_{g x}=F_{g} \sin \theta$

$F_{g x}=m g \sin \theta$

$F_{g x}=(7.0)(9.81) \sin 35$

$F_{g x}=39.3473 \mathrm{~N}$ 
The force of friction, $F_{f}$

$F_{f}=\mu_{k} m g \cos \theta$

$F_{f}=(0.45)(7.0)(9.81) \cos \theta$

$F_{f}=25.2872 \mathrm{~N}$

Step III: Calculate the net force in the direction of motion

In this case both the forces opposite to the direction of motion; and therefore both are negative

$F_{n e t}=-F_{g x}-F_{f}$

$F_{\text {net }}=-39.3473-25.2872$

$F_{n e t}=-64.6345 N$

$a=\frac{F_{\text {net }}}{m}$

$a=\frac{-64.6345}{7}$

$a=9.2 \mathrm{~m} / \mathrm{s}^{2}$ (opposite direction of motion)

In our case

$\mathrm{m}=3 \mathrm{~kg}$

$\theta=6^{\circ}$

$\mu=0.08$----for ball bearing to steel friction

Thus,

$F_{g x}=3 \times 9.81 \times \sin (6)$

$F_{g x}=3.076 \mathrm{~N}$

$F_{f}=\mu m g \cos \theta$

\section{Observations:}

Observations for Angle of inclination 8 degree incline
$=0.08 \times 3 \times 9.81 \times \cos (6)=2.34 \mathrm{~N}$

Thus

$$
F_{n e t}=-F_{g x}-F_{f}
$$$$
=3.076-2.34=0.736 \mathrm{~N}
$$

Now, $F_{\text {net }}=(m)(a)$

$a=\frac{F_{n e t}}{m}$

$a=\frac{0.736}{3}$

$\mathrm{a}=0.245 \mathrm{~m} / \mathrm{sec}^{2}$

Now,

Co-relation between velocity and acceleration

$V_{f}{ }^{2}=V_{i}^{2}+a \times d$

Here

$\mathrm{V}_{\mathrm{f}}=$ Final velocity of tray $\mathrm{m} / \mathrm{sec}$

$\mathrm{d}$ = distance travelled by tray $=1 \mathrm{~m}$

As the initial velocity of tray $\mathrm{V}_{\mathrm{i}}=0$

$V_{f}=\sqrt{(a \times d)}$

$V_{f}=\sqrt{(0.245 \times 1)}$

$V_{f}=0.495 \mathrm{~m} / \mathrm{sec}$

Thus,

Time required to travel from point (a) to point (b) with mass of $3 \mathrm{~kg}$ and angle of inclination 6 degree,

$=$ Distance of point (a) to Point (b) $/ \mathrm{V}_{\mathrm{f}}=1 / 0.495$ $=2.01$ seconds.

\section{inclination 8 degree incline}

\begin{tabular}{|c|c|c|c|c|c|c|c|c|c|}
\hline load (L) & angle & $\mathrm{F}_{\mathrm{gx}}$ & $\mathrm{F}_{\mathrm{f}}$ & $\mathrm{F}_{\text {net }}$ & $\mathrm{a}$ & $\mathrm{V}_{\mathrm{f}}$ & Dist & Time(s) & $\begin{array}{c}\text { Actual } \\
\text { time(s) }\end{array}$ \\
\hline 3 & 8 & 4.1202 & 2.331468 & 1.788732 & 0.596244 & 0.772168 & 1 & 1.295054 & 2.5 \\
\hline 4 & 8 & 5.4936 & 3.108624 & 2.384976 & 0.596244 & 0.772168 & 1 & 1.295054 & 2.3 \\
\hline 5 & 8 & 6.867 & 3.88578 & 2.98122 & 0.596244 & 0.772168 & 1 & 1.295054 & 2.1 \\
\hline 6 & 8 & 8.2404 & 4.662936 & 3.577464 & 0.596244 & 0.772168 & 1 & 1.295054 & 2 \\
\hline
\end{tabular}




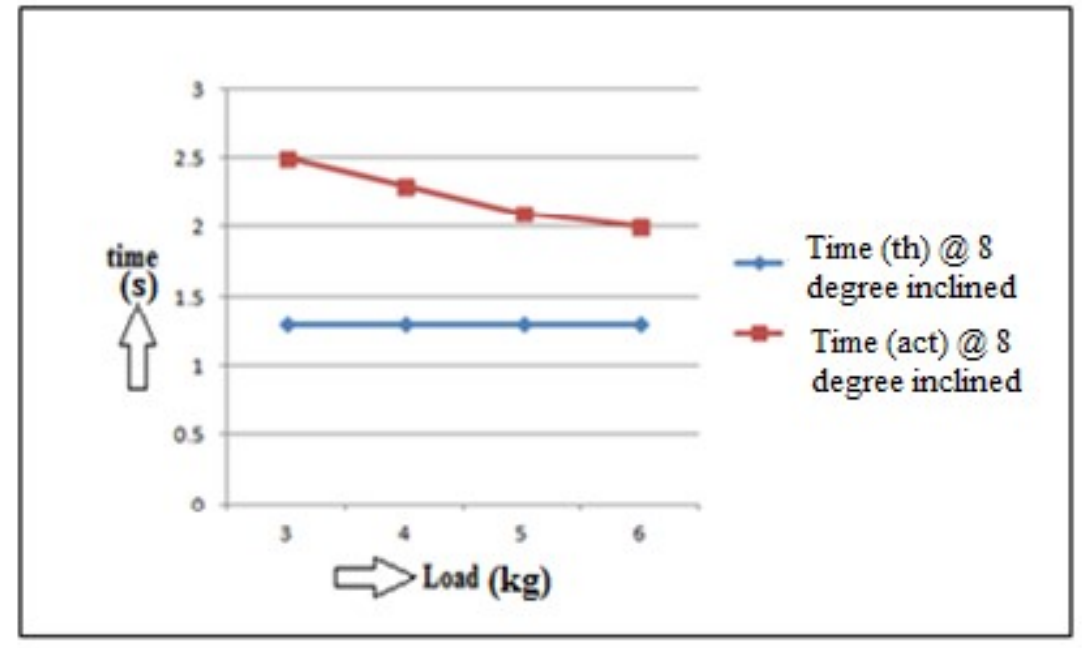

Graph: time vs load for 8 degree inclination

Observations for Angle of inclination

7degree incline

\begin{tabular}{|l|l|l|l|l|l|l|l|l|l|}
\hline load (L) & angle & $\mathrm{F}_{\mathrm{gx}}$ & $\mathrm{F}_{\mathrm{f}}$ & $\mathrm{F}_{\text {net }}$ & $\mathrm{a}$ & $\mathbf{V}_{\mathrm{f}}$ & Dist & Time(s) & $\begin{array}{l}\text { Actual } \\
\text { time(s) }\end{array}$ \\
\hline 3 & 7 & 3.59046 & 2.336742 & 1.253718 & 0.417906 & 0.646456 & 1 & 1.546895 & 2.9 \\
\hline 4 & 7 & 4.78728 & 3.115656 & 1.671624 & 0.417906 & 0.646456 & 1 & 1.546895 & 2.5 \\
\hline 5 & 7 & 5.9841 & 3.89457 & 2.08953 & 0.417906 & 0.646456 & 1 & 1.546895 & 2.3 \\
\hline 6 & 7 & 7.18092 & 4.673484 & 2.507436 & 0.417906 & 0.646456 & 1 & 1.546895 & 2.2 \\
\hline
\end{tabular}

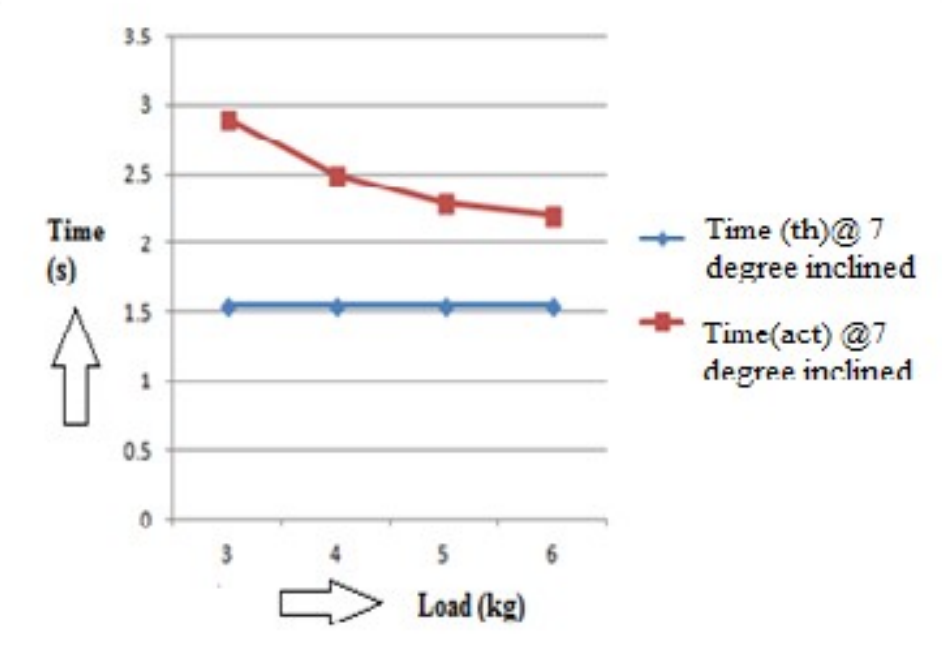

Graph time vs load for 7 degree inclination

Observations for Angle of inclination 6 degree:

\begin{tabular}{|c|c|c|c|c|c|c|c|c|c|}
\hline $\begin{array}{c}\text { load } \\
(\mathrm{L})\end{array}$ & angle & $\mathrm{F}_{\mathrm{gx}}$ & $\mathrm{F}_{\mathrm{f}}$ & $\mathrm{F}_{\text {net }}$ & $\mathrm{a}$ & $\mathbf{V}_{\mathrm{f}}$ & Dist & Time(s) & $\begin{array}{c}\text { Actual time } \\
(\mathrm{s})\end{array}$ \\
\hline 3 & 6 & 3.075435 & 2.330856 & 0.744579 & 0.248193 & 0.49819 & 1 & 2.007267 & 4 \\
\hline 4 & 6 & 4.10058 & 3.107808 & 0.992772 & 0.248193 & 0.49819 & 1 & 2.007267 & 3.5 \\
\hline 5 & 6 & 5.125725 & 3.88476 & 1.240965 & 0.248193 & 0.49819 & 1 & 2.007267 & 3 \\
\hline 6 & 6 & 6.15087 & 4.661712 & 1.489158 & 0.248193 & 0.49819 & 1 & 2.007267 & 3 \\
\hline
\end{tabular}




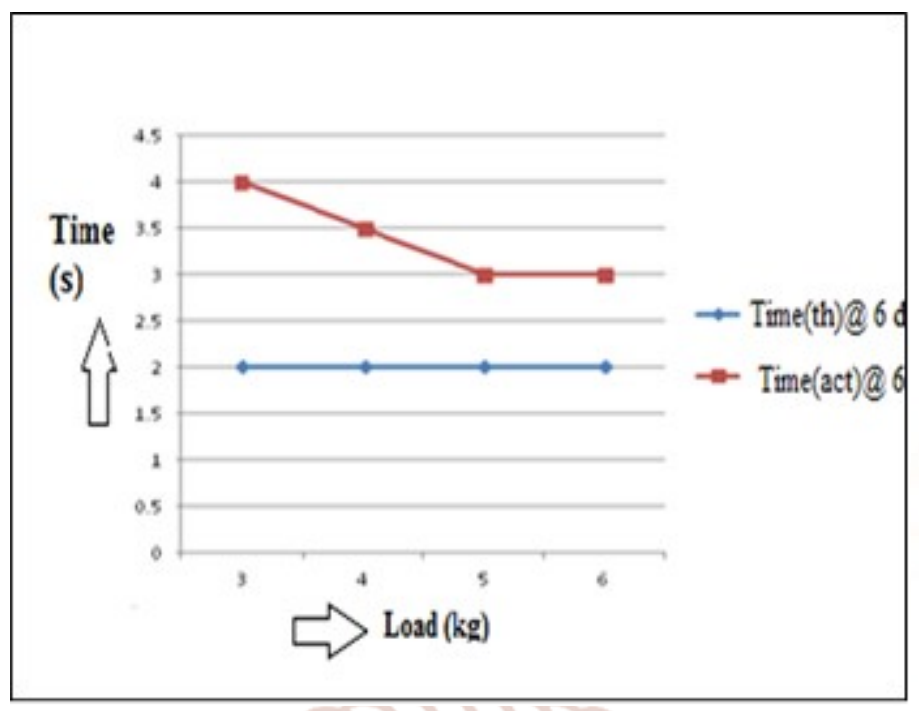

Graph time vs load for 6 degree inclination

Observations for Angle of inclination 5 degree:

\begin{tabular}{|l|l|l|l|l|l|l|l|l|l|}
\hline load (L) & angle & $\mathrm{F}_{\mathrm{gx}}$ & $\mathrm{F}_{\mathrm{f}}$ & $\mathrm{F}_{\text {net }}$ & $\mathrm{a}$ & $\mathrm{V}_{\mathrm{f}}$ & Dist & Time(s) & $\begin{array}{l}\text { Actual } \\
\text { time(s) }\end{array}$ \\
\hline 3 & 5 & 2.56041 & 2.345218 & 0.215192 & 0.071731 & 0.267826 & 1 & 3.733769 & 5 \\
\hline 4 & 5 & 3.41388 & 3.126957 & 0.286923 & 0.071731 & 0.267826 & 1 & 3.733769 & 5.5 \\
\hline 5 & 5 & 4.26735 & 3.908696 & 0.358654 & 0.071731 & 0.267826 & 1 & 3.733769 & 5.2 \\
\hline 6 & 5 & 5.12082 & 4.690436 & 0.430384 & 0.071731 & 0.267826 & 1 & 3.733769 & 4.6 \\
\hline
\end{tabular}

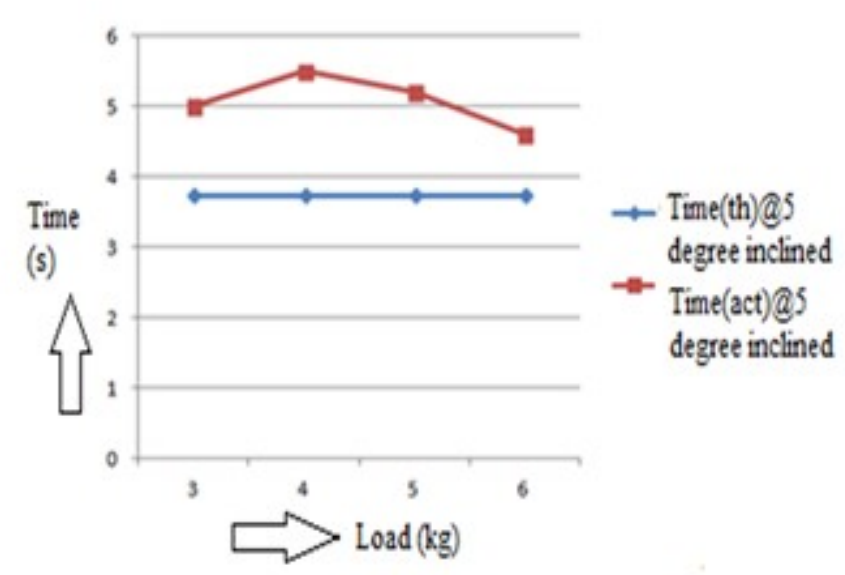

\section{Graph: time vs load for 5 degree inclination}

Observations and graphs indicate that the theoretical time of transfer remains unchanged with increase in load but the actual time lowers with increase in load due to effect of gravitational acceleration.

So also the theoretical time is less as compared to the actual time indicating friction present in slide and also due to the fact that the friction in rope and pulley is un-accounted in theoretical calculations.

\section{Economic Analysis of the Linear Conveyor:}

Considering that the time required by the operator to move from Point (a) to Point (b) by time and motion study to be 10 seconds the effect of using gravity linear conveyor can be studied from figure below:

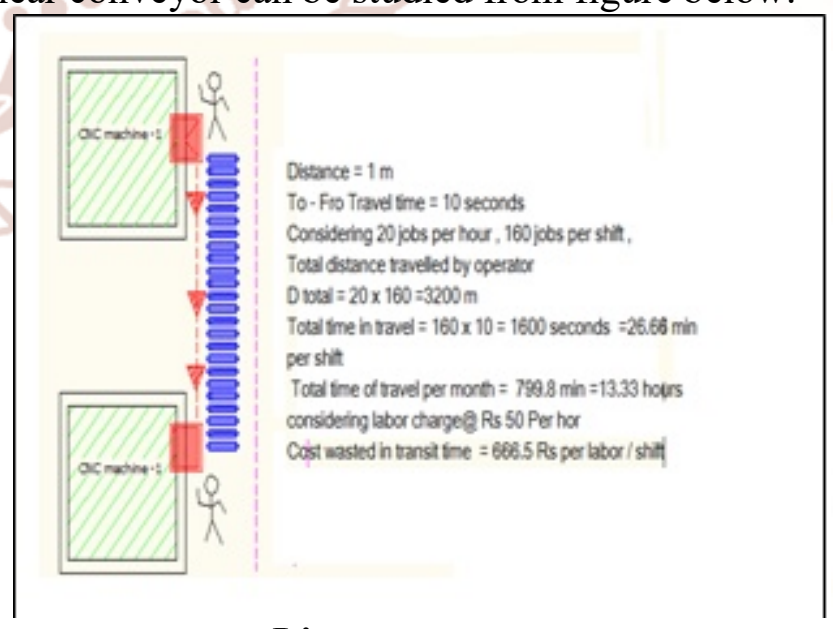

\section{Linear conveyor}

Thus from above analysis it is clear that the cost of Rs $660 /$ - per shift per machine will be saved by the linear conveyor. Considering that the conveyor is operated for two shifts per day the cost of conveyor 
will be recovered in $(16000 /(660 \times 2))=12$ months

i.e. 1-year time.

\section{TEST \& TRIAL ON ROTARY CONVEYOR:}

Observations for Angle of inclination 5 degree:

\section{Inclination 5 degree incline}

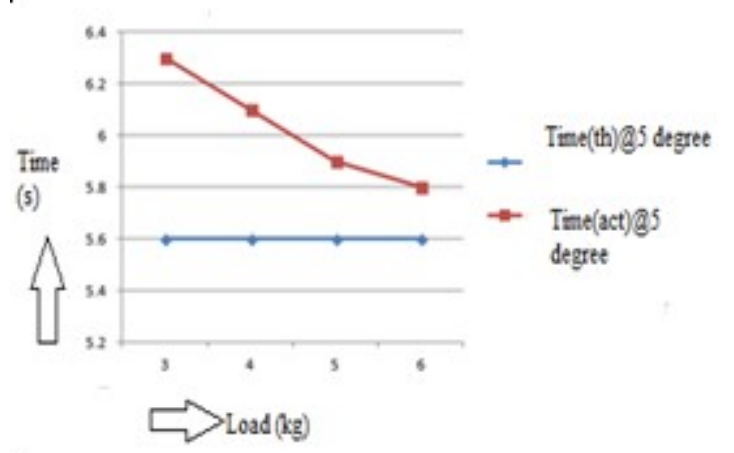

\begin{tabular}{|l|l|l|l|l|l|l|l|l|l|}
\hline $\begin{array}{l}\text { load } \\
(\mathrm{L})\end{array}$ & angle & $\mathrm{F}_{\mathrm{gx}}$ & $\mathrm{F}_{\mathrm{f}}$ & $\mathrm{F}_{\text {net }}$ & $\mathbf{A}$ & $\mathbf{V}_{\mathrm{f}}$ & Dist & Time & $\begin{array}{l}\text { Actual } \\
\text { time(s) }\end{array}$ \\
\hline 3 & 5 & 2.56041 & 2.345218 & 0.215192 & 0.071731 & 0.267826 & 1.5 & 5.600653 & 6.3 \\
\hline 4 & 5 & 3.41388 & 3.126957 & 0.286923 & 0.071731 & 0.267826 & 1.5 & 5.600653 & 6.1 \\
\hline 5 & 5 & 4.26735 & 3.908696 & 0.358654 & 0.071731 & 0.267826 & 1.5 & 5.600653 & 5.9 \\
\hline 6 & 5 & 5.12082 & 4.690436 & 0.430384 & 0.071731 & 0.267826 & 1.5 & 5.600653 & 5.8 \\
\hline
\end{tabular}

Graph time vs load for 5 degree

\section{CONCLUSION}

After the fabrication and implementation of the effective material handling system, one could easily demonstrate the improved material handling. Both the system: Linear Material Handling (Powerless conveyors) and Revolving Material Handling Systems, shows how some simple and innovative ideas can be used to develop economical and non power consuming Material Handling Systems that can significantly relieve the operator fatigue, make the Material Handling safer along with the increased productivity. The project was just an effort to demonstrate the need and means of improving the Material Handling Systems and highlight the future scope of effective Material Handling.

\section{FUTURE SCOPE:}

Endless efforts can be made to continuously improve upon the material handling systems. The use of revolving material handling system concept would cut upon the cost and labour involved in material handling to a great extent.
It is possible to completely replace the powered conveyors by innovative thinking and utilizing gravity. The concept lets the door open for entire low cost automation of the line.

The project shows that the equipments can be easily implemented parallel to all similar application areas. The use of such material handling systems is possible in almost all small to large scale production industries. One may easily predict that the Revolving Material Transfer System would prove to be a revolutionary concept for industrial development.

\section{REFERENCES:}

1. Ghazi Abu Taher, 2Yousuf Howlader, 3Md. Asheke Rabbi, 4Fahim Ahmed Touqir, "Automation Of Material Handling With Bucket Elevator And Belt Conveyor", International Journal Of Scientific And Research Publications, Volume 4, Issue 3, March 20141 Issn2250-3153

2. S.S. Gaikwad, 2E.N. Aitavade Static Analysis Of A Roller Of Gravity Roller Conveyor For Structural \& Weight optimization International 
Journal of Advanced Engineering Technology EISSN 0976-3945 Oct-Dec.,2013/27-30

3. Shalom Akhai, 2Harpreet Singh, "Design Optimization For Modification Of Trough Belt Conveyor To Reduce Material Spillage Used In Clinker Transport In Cement Plant", International Journal Of Research In Advent Technology Volume 1, Issue 4, , E-Issn: 2321-9637,November 2013

4. IBT White Paper: Specification of a Package Handling Conveyor System

5. S. M. Shinde [1], R.B. Patil [2]Optimization Technique Used for the Roller Conveyor System for Weight Reduction International Journal of Engineering Research \& Technology (IJERT) Vol. 1 Issue 5, July - 2012 ISSN: 2278-0181

6. Yasushi Shibata "Environmental report Prevention of Global Warming”, Karakuri Improvements are Spreading and Expanding in Japan and overseas March 2010.

7. Rick Garrity "The Basics of Conveyors (Belt, Roller, Gravity)" perspectives |r on material handling practices.

8. M. A. Alspaugh, "Latest Developments in Belt Conveyor Technology". September 27, 2004.

9. Gravity conveyor catalog

10. P.J. Witt , 2 K.G. Carey, 3 T.V. Nguyen Prediction of dust loss from conveyors using computational fluid dynamics modeling csiro, Division Of Minerals, Box 312, Clayton South, Vic. 3169, Australia 24 April 2001 